\title{
Modelling of High Frequency Converter Transformer with Floating Active Inductor
}

\author{
Mustafa Konal $^{1}$, Mehmet Onur Gulbahce ${ }^{2}$, Cengiz Polat Uzunoglu ${ }^{3}$, Firat Kacar ${ }^{3}$ \\ ${ }^{1}$ Department of Electronics and Telecommunication Eng., Namik Kemal University, \\ Tekirdag, Turkey \\ ${ }^{2}$ Department of Electrical Engineering, Istanbul Technical University, \\ Istanbul, Turkey \\ ${ }^{3}$ Department of Electrical and Electronics Engineering, Istanbul University-Cerrahpasa, \\ Istanbul, Turkey \\ mustafa.konal@istanbul.edu.tr
}

\begin{abstract}
As number of digital electronics and power electronics based devices has risen recently, the fields of application for high frequency transformers have been increased. Aircraft industry, solar converters, electric drives, medical imaging systems and similar applications contain high frequency transformer operations. To express proper operation of transformers, equivalent circuit based analysis is conducted for typical transformers in which circuit parameters obtained. Rather than a conventional equivalent circuit analysis, a delicate analysis based on novel floating active inductor employed equivalent circuit is proposed for modelling of high frequency transformer characteristics. In this study, high frequency operated $2500 \mathrm{~W} 311 \mathrm{~V} / 200 \mathrm{~V}$ transformer is investigated for frequency spectrum between $20 \mathrm{kHz}$ and $200 \mathrm{kHz}$. Measured characteristics of investigated transformer are compared with the characteristics of proposed equivalent circuit. Proposed floating active inductor is designed with MOSFETs and can be tuned for wide frequency spectrum adaptively. In addition, proposed equivalent circuit is capable of modelling various high frequency transformers for different frequency values.
\end{abstract}

Index Terms-High-frequency transformers; Active inductors; Transconductance; Equivalent circuits.

\section{INTRODUCTION}

It is very common way to model transformers with their equivalent circuits based on their losses. Iron losses and copper losses are the key signatures for determining shunt admittances and the series impedances related with core and windings [1], [2]. For higher frequencies flux penetration into the core of the transformer is limited [3]. Besides varying frequency values of the input source, end up with different inductance values in the equivalent circuit in which modification of the equivalent circuit is mandatory. Another shortcoming is the single equivalent circuit representation for specific condition where rated values of the transformer are chosen as the inputs for the short circuit and open circuit tests. To overcome these bottlenecks an adaptive equivalent circuit for high frequency transformers or high frequency operated conventional transformers is proposed.

High frequency transformers are frequently employed in

Manuscript received 27 March, 2018; accepted 30 August, 2018. solar converters, electric drives, medical imaging systems, the aircraft industry, power conversion applications [4]-[8] etc. Although there are several applications for modelling high frequency transformer [9], [10], there is not any such similar study, which enables VDTA, based active inductor on high frequency transformer modelling.

In this study, $311 \mathrm{~V} / 200 \mathrm{~V} 2500 \mathrm{~W} 100 \mathrm{kHz}$ high frequency full bridge converter transformer is investigated for real case scenario. The tests are conducted for frequencies between $20 \mathrm{kHz}$ and $200 \mathrm{kHz}$ where overloading in terms of excessed frequency is additionally analysed. At the higher frequencies, iron losses on the core are accelerated due to increased variations of magnetic fluxes where shunt inductances are dominant in the equivalent circuit. For this purpose, simplified equivalent circuit is derived by open circuit tests for different frequency values [1]. In addition, stray capacitances for high frequency transformer are introduced in various studies however; their effects are displayed under resonance conditions [11]. According to the tests for different frequency values, different inductances are necessity in terms of equivalent circuit. As a novel approach, proposed active inductor is employed for simulating core inductances in the equivalent circuit.

Several floating active inductor circuits employing different active elements such as electronically controllable current conveyor (ECCC) [12], current differencing transconductance amplifier (CDTA) [13], dual-output differential difference current conveyor (DO-DDCC) [14], voltage differencing transconductance amplifiers (VDTA) [15], Z-copy current follower transconductance amplifier (ZC-CFTA) [16], Z-copy voltage differencing transconductance amplifier (ZC-VDTA) [17], operational transconductance amplifier (OTA) [18] have been investigated in the literature. In this study, VDTA based floating active inductor circuit is employed for modelling of high frequency converter transformer, which is proposed by Yesil [19]. The key characteristics of the floating active inductor circuit has been verified by using SPICE simulation with TSMC CMOS $0.18 \mu \mathrm{m}$ process parameters. Based on high frequency characteristics of proposed active inductor, it 
is employed to model investigated transformer since operation bandwidth of the inductor is quite satisfying.

This paper can be summarized as follows. In Section II, the test setup for high frequency transformer and equivalent circuit are explained. In Section III the floating active inductor is introduced. In Section IV, the test results and spice simulation results are provided for comparison purposes. Finally, in Section V, the conclusion is given.

\section{TEST SETUP}

The test setup contains high frequency $311 \mathrm{~V} / 200 \mathrm{~V}$ $2500 \mathrm{~W} 100 \mathrm{kHz}$ full bridge converter transformer, a signal generator and a high speed oscilloscope. In order to obtain high frequency sinusoidal, a signal generator with $20 \mathrm{~V}_{\mathrm{pp}}$ amplitude output is applied from the HV side $(311 \mathrm{~V})$ of the transformer where LV side is open circuited. In order to investigate transformer characteristics while excessive frequency sinusoidal signals are applied transformer is operated lower voltages than the ratings. The test setup is given in Fig. 1.

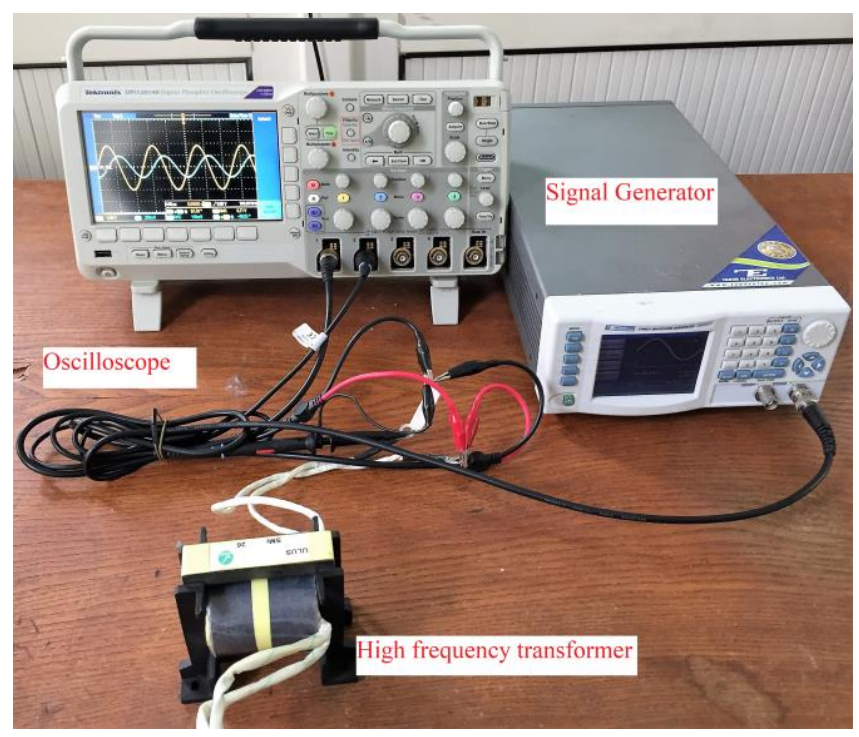

Fig. 1. Test setup.

The equivalent circuit is based on core admittances (especially inductor) where flux penetrations are bounded under high frequency conditions [1]. During the tests magnetizing inductances, phase angles and input currents are obtained for different frequency values. The simplified equivalent circuit for proposed setup under high frequency conditions is given in Fig. 2 [1].



Fig. 2. High frequency transformer simplified model.

In the equivalent circuit $\mathrm{L}_{\mathrm{M}}$ is the magnetizing inductance based on transformer's core characteristics where the ideal transformer is employed for electrical isolation purposes. In the test procedure primary voltage $\left(v_{1}\right)$ and current $\left(i_{1}\right)$ is recorded via oscilloscope while the secondary is open circuited.

\section{FLOATING ACTIVE INDUCTOR}

The floating active inductor circuit for modelling high frequency transformer is realized with VDTA. The terminal relationships of an ideal VDTA can be characterized by

$$
\left.\left\lfloor\begin{array}{l}
I_{Z} \\
I_{X+} \\
I_{X-}
\end{array}\right\rfloor=\left\lfloor\begin{array}{ccc}
g_{m 1} & -g_{m 1} & 0 \\
0 & 0 & g_{m 2} \\
0 & 0 & -g_{m 2}
\end{array}\right\rfloor \mid \begin{array}{l}
V_{V P} \\
V_{V N} \\
V_{Z}
\end{array}\right\rfloor .
$$

The $g_{\mathrm{m}} \mathrm{s}$ are transconductance values of the VDTA model. The circuit symbol and the CMOS realization of the VDTA are shown in Fig. 3. The VDTA circuit is implemented with improved floating current sources as shown in Fig. 3(b) [19].

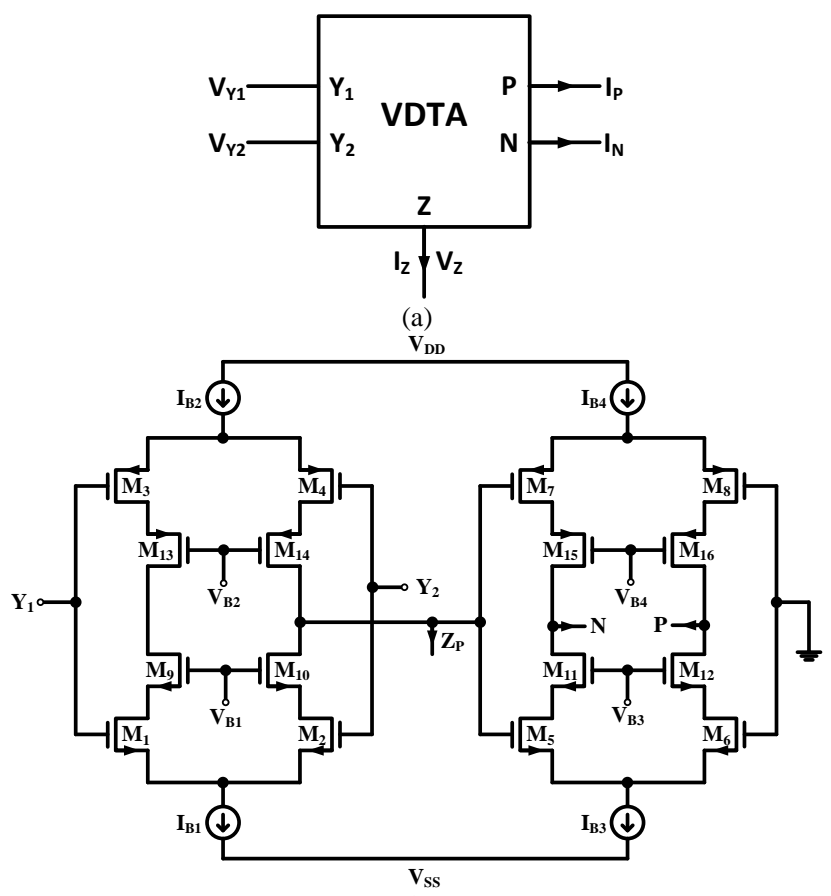

(b)

Fig. 3. Circuit symbol (a); CMOS realization of the VDTA (b)

The VDTA based floating active inductor configuration is given in Fig. 4. The simulations are performed with LTSPICE program using TSMC CMOS $0.18 \mu \mathrm{m}$ process parameters. The aspect ratios of the transistors are given in Table I. Supply voltages are taken as $\mathrm{V}_{\mathrm{DD}}=-\mathrm{V}_{\mathrm{SS}}=0.9 \mathrm{~V}$ where $\mathrm{I}_{\mathrm{B} 1}=\mathrm{I}_{\mathrm{B} 2}=\mathrm{I}_{\mathrm{B} 3}=\mathrm{I}_{\mathrm{B} 4}=10 \mu \mathrm{A}$ biasing currents and $\mathrm{V}_{\mathrm{b} 1}=\mathrm{V}_{\mathrm{b} 3}=-\mathrm{V}_{\mathrm{b} 2}=-\mathrm{V}_{\mathrm{b} 4}=0.2 \mathrm{~V}$ voltages for bias are used.

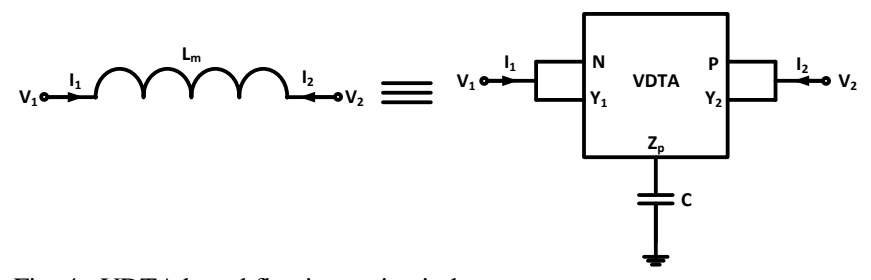

Fig. 4. VDTA based floating active inductor.

The proposed floating active inductor circuit is electronically tunable. Thus, different impedance values are obtained adaptively for modelling high frequency 
transformer characteristics by changing value of the capacitor $\mathrm{C}$. The ideal and simulated magnitude response of the floating active inductor is shown in Fig. 5 for the inductance value of $0.82 \mathrm{mH}$ which is empirically measured for proposed high frequency full bridge converter transformer.

TABLE I. ASPECT RATIOS OF THE TRANSISTORS.

\begin{tabular}{|c|c|c|}
\hline Transistors & $\mathbf{W}(\boldsymbol{\mu m})$ & $\mathbf{L}(\boldsymbol{\mu m})$ \\
\hline $\mathrm{M}_{1}, \mathrm{M}_{2}, \mathrm{M}_{5}, \mathrm{M}_{6}$ & 18 & 0.54 \\
\hline $\mathrm{M}_{3}, \mathrm{M}_{4}, \mathrm{M}_{7}, \mathrm{M}_{8}$ & 72 & 0.54 \\
\hline $\mathrm{M}_{9}, \mathrm{M}_{10}, \mathrm{M}_{11}, \mathrm{M}_{12}$ & 108 & 0.54 \\
\hline $\mathrm{M}_{13}, \mathrm{M}_{14}, \mathrm{M}_{15}, \mathrm{M}_{16}$ & 180 & 0.54 \\
\hline
\end{tabular}

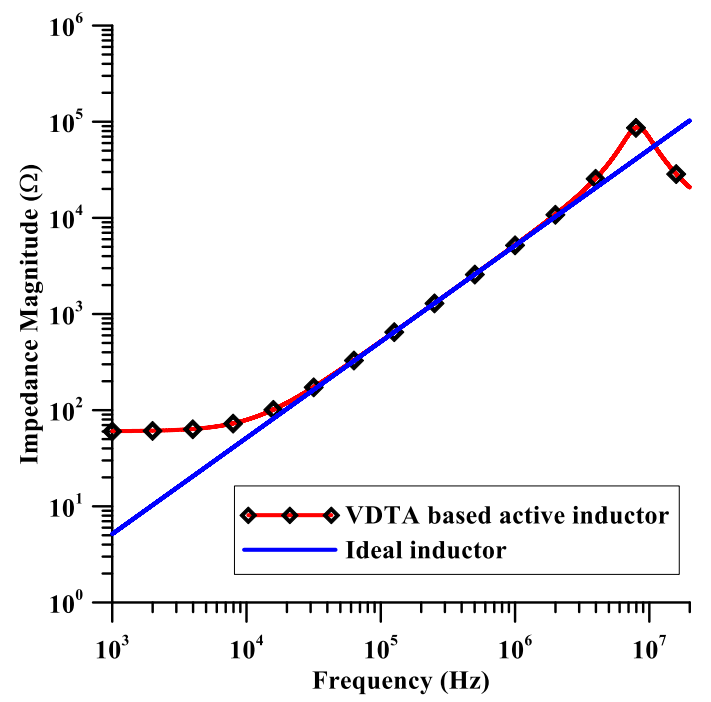

Fig. 5. Impedance variation of proposed VDTA based floating active inductor and ideal inductor for different frequencies.

It is obvious that the floating active inductor can be operated between $20 \mathrm{kHz}$ and $2 \mathrm{GHz}$ frequency range effectively. This region is not fixed region for the model; on the contrary, this region can be shifted to desired region by tuning VDTA for required frequencies.

\section{RESUlTS AND DiscUSSION}

During the tests full bridge converter transformer is employed for different frequency values. Supply voltages (root mean square-RMS), phase differences, magnetizing currents and magnetizing inductances are measured and given in Table II.

Although test transformer is rated $100 \mathrm{kHz}$, tests are conducted up to $200 \mathrm{kHz}$ for overload conditions. In order to verify reliability of the proposed model with floating active inductor, the SPICE model is investigated and related characteristics are observed under same conditions with transformer tests. SPICE model characteristics are given in Table III.

Magnetizing currents and phase angles are analysed for equivalent model capabilities under different frequencies. Both model and test transformer characteristics exhibit similar results except for $20 \mathrm{kHz}$ frequency at which VDTA based active inductor displays slight difference with ideal inductor. The proposed model can be tuned for desired frequency values however; in this study, the initial value is chosen as $20 \mathrm{kHz}$ to underline tuning characteristics of proposed SPICE model with VDTA based active inductor.

TABLE II. HIGH FREQUENCY TRANSFORMER CHARACTERISTICS.

\begin{tabular}{|c|c|c|c|c|}
\hline $\begin{array}{c}\text { Frequency } \\
(\mathbf{k H z})\end{array}$ & $\begin{array}{c}\text { Primary } \\
\text { Voltage } \\
(\mathbf{V})\end{array}$ & $\begin{array}{c}\text { Phase } \\
\text { Angle } \\
\text { (Degree) }\end{array}$ & $\begin{array}{c}\text { Magnetizing } \\
\text { Current } \\
(\mathbf{m A})\end{array}$ & $\begin{array}{c}\text { Magnetizing } \\
\text { Inductance } \\
(\mathbf{m H})\end{array}$ \\
\hline 20,00 & 5,54 & 82,27 & 55,00 & 0,80 \\
\hline 30,00 & 6,10 & 84,95 & 40,54 & 0,80 \\
\hline 40,00 & 6,37 & 84,93 & 31,68 & 0,80 \\
\hline 50,00 & 6,51 & 86,40 & 26,15 & 0,79 \\
\hline 60,00 & 6,59 & 85,34 & 22,03 & 0,79 \\
\hline 70,00 & 6,64 & 85,87 & 19,15 & 0,79 \\
\hline 80,00 & 6,84 & 86,26 & 16,37 & 0,83 \\
\hline 90,00 & 6,58 & 85,79 & 15,06 & 0,77 \\
\hline 100,00 & 6,48 & 85,47 & 13,06 & 0,79 \\
\hline 110,00 & 6,55 & 84,38 & 11,64 & 0,81 \\
\hline 120,00 & 6,40 & 85,30 & 11,06 & 0,77 \\
\hline 130,00 & 6,61 & 86,45 & 9,91 & 0,82 \\
\hline 140,00 & 6,46 & 85,96 & 9,48 & 0,78 \\
\hline 150,00 & 6,54 & 87,07 & 8,78 & 0,79 \\
\hline 160,00 & 6,62 & 86,44 & 8,13 & 0,81 \\
\hline 170,00 & 6,50 & 84,99 & 7,81 & 0,78 \\
\hline 180,00 & 6,50 & 84,08 & 7,38 & 0,78 \\
\hline 190,00 & 6,45 & 84,11 & 7,05 & 0,77 \\
\hline 200,00 & 6,59 & 84,82 & 6,55 & 0,80 \\
\hline & & & & \\
\hline
\end{tabular}

TABLE III. SPICE MODEL CHARACTERISTICS.

\begin{tabular}{|c|c|c|c|c|}
\hline $\begin{array}{c}\text { Frequency } \\
(\mathbf{k H z})\end{array}$ & $\begin{array}{c}\text { Primary } \\
\text { Voltage (V) }\end{array}$ & $\begin{array}{c}\text { Phase } \\
\text { Angle } \\
\text { (Degree) }\end{array}$ & $\begin{array}{c}\text { Magnetizing } \\
\text { Current } \\
(\mathbf{m A})\end{array}$ & $\begin{array}{c}\text { Magnetizing } \\
\text { Inductance } \\
(\mathbf{m H})\end{array}$ \\
\hline 20,00 & 5,54 & 68,00 & 51,10 & 0,80 \\
\hline 30,00 & 6,10 & 74,90 & 39,00 & 0,80 \\
\hline 40,00 & 6,37 & 78,52 & 30,96 & 0,80 \\
\hline 50,00 & 6,51 & 80,66 & 25,33 & 0,79 \\
\hline 60,00 & 6,59 & 82,24 & 21,44 & 0,79 \\
\hline 70,00 & 6,64 & 80,16 & 18,40 & 0,79 \\
\hline 80,00 & 6,84 & 81,38 & 16,64 & 0,83 \\
\hline 90,00 & 6,58 & 82,28 & 14,20 & 0,77 \\
\hline 100,00 & 6,48 & 83,00 & 12,50 & 0,79 \\
\hline 110,00 & 6,55 & 83,58 & 11,42 & 0,81 \\
\hline 120,00 & 6,40 & 84,00 & 10,29 & 0,77 \\
\hline 130,00 & 6,61 & 84,46 & 9,77 & 0,82 \\
\hline 140,00 & 6,46 & 84,80 & 8,83 & 0,78 \\
\hline 150,00 & 6,54 & 85,08 & 8,30 & 0,79 \\
\hline 160,00 & 6,62 & 85,33 & 7,86 & 0,81 \\
\hline 170,00 & 6,50 & 85,54 & 7,21 & 0,78 \\
\hline 180,00 & 6,50 & 85,71 & 6,80 & 0,78 \\
\hline 190,00 & 6,45 & 85,87 & 6,37 & 0,77 \\
\hline 200,00 & 6,59 & 86,00 & 6,16 & 0,80 \\
\hline & & & & \\
\hline
\end{tabular}

In the model magnetizing current defines shunt magnetizing reactance and hence inductance of the core. The experimental and SPICE model magnetizing currents are given in Fig. 6. The phase difference of an operating transformer is distinctive characteristic where angle lags are observed. Inductive impedances in the equivalent model satisfies that the voltage leads current. Phase differences of supply voltage and measures input current for different frequencies are shown in Fig. 7.Except for intentionally chosen $20 \mathrm{kHz}$, the phase differences are quite similar (approximately 80 degrees-85 degrees) between voltage and current. Especially for rated frequency values 
(approximately $100 \mathrm{kHz}$ ), the phase differences are too close to compare.

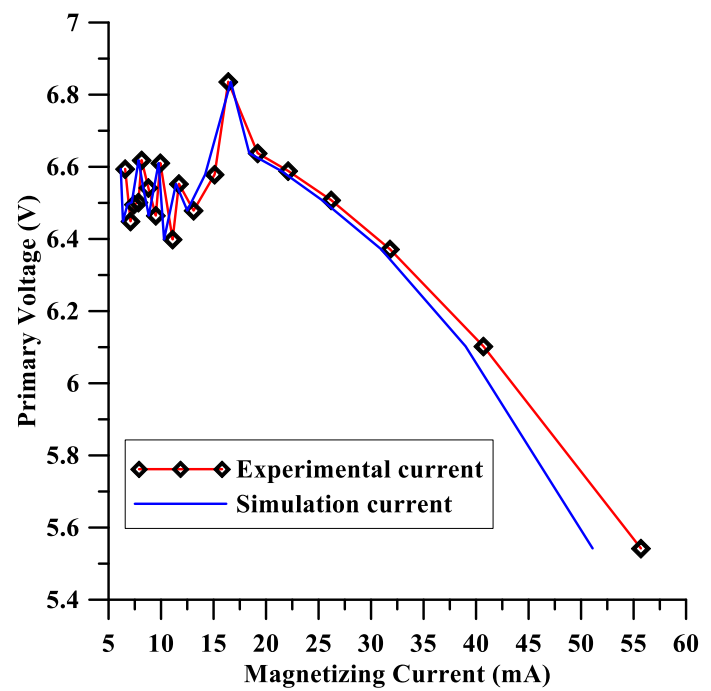

Fig. 6. Measured currents of proposed model and test transformer.

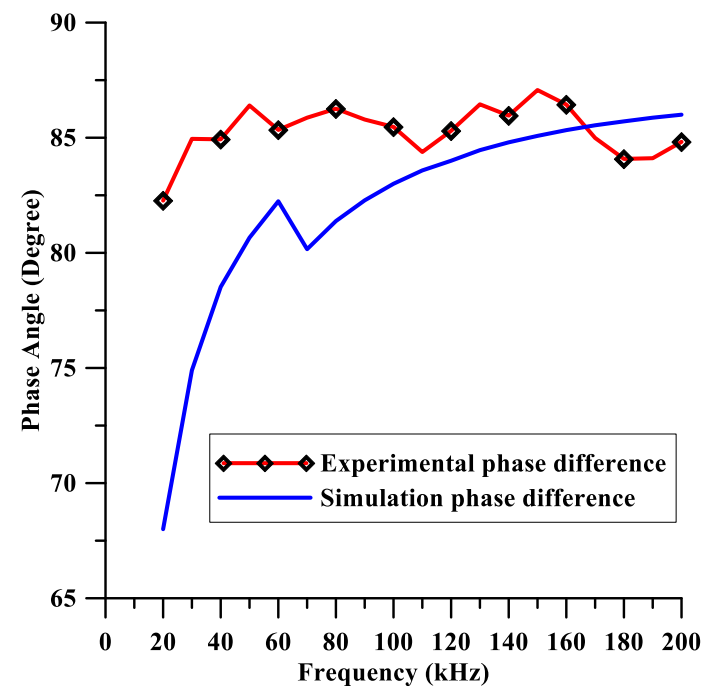

Fig. 7. Phase differences for different frequencies.

\section{CONCLUSIONS}

Increased frequencies in transformer applications accelerate frequency related core losses and hence magnetizing currents. It is challenging task to propose single equivalent model for high frequency transformers since varying system characteristics leads to different models for different inputs. For this purpose, an adaptive equivalent model for high frequency transformer applications in which magnetizing inductor is simulated with floating active inductor is proposed. VDTA based floating active inductor have satisfying characteristics such as increased bandwidth, electronically tunability and active element employed. As an active element based structure, VDTA promises semiconductor based electronic integration for modelling in high frequency applications especially for high frequency transformer. Besides, due to the tuning characteristics of proposed model it is plausible to simulate various inductor applications for higher frequencies. The proposed model is capable of simulating high frequency transformers where magnetizing inductance impedances (from $100 \Omega$ to $100 \mathrm{k} \Omega$ based on frequency) and related losses are quite significant.
Proposed model is capable of simulating high frequency transformer in terms of magnetizing inductances for wide frequency range from $20 \mathrm{kHz}$ to $200 \mathrm{kHZ}$ (which is adjustable). Various applications such as solar converters, electric drives, medical imaging systems, the aircraft industry, power applications require flexible transformer modelling where proposed model is quite effective.

\section{REFERENCES}

[1] R. W. Erickson, Fundamentals of Power Electronics. Springer, 2012.

[2] S. K. Mukerji, M. George, "Augmented short-circuit test for the measurement of transformer equivalent-circuit parameters with large series branch impedances", International Journal of Electrical Engineering Education, vol. 47, no. 1, pp. 86-93, 2010. DOI: 10.7227/IJEEE.47.1.8.

[3] B. Jurisic, I. Uglesic, A. Xemard, F. Paladian, "Difficulties in high frequency transformer modelling", Electric Power Systems Research, vol. 138, pp. 25-32, 2016. DOI: 10.1016/j.epsr.2016.02.009.

[4] M. Jafari, Z. Malekjamshidi, G. Lei, T. Wang, G. Platt, J. Zhu, "Design and implementation of an amorphous high-frequency transformer coupling multiple converters in a smart microgrid", in IEEE Trans. Ind. Elec., vol. 64, no. 2, pp. 1028-1037, 2017. DOI: 10.1109/TIE.2016.2583401.

[5] M. Pahlevaninezhad, D. Hamza, P. K. Jain, "An improved layout strategy for common-mode emi suppression applicable to highfrequency planar transformers in high-power DC/DC converters used for electric vehicles", in IEEE Trans. Power Electronics, vol. 29, no. 3, pp. 1211-1228, 2014. DOI: 10.1109/TPEL.2013.2260176.

[6] H. Peng, J. Sabate, K. A. Wall, J. S. Glaser, "GaN-based high frequency high energy delivery transformer push-pull inverter for ultrasound pulsing application", in IEEE Trans. Power Electronics, no. 99, pp. 1-1, 2017. DOI: 10.1109/TPEL.2017.2754343.

[7] B. Karanayil, M. Ciobotaru, V. G. Agelidis, "Power flow management of isolated multiport converter for more electric aircraft", in IEEE Trans. on Power Elec., vol. 32, no. 7, pp. 5850 5861, 2017. DOI: 10.1109/TPEL.2016.2614019.

[8] B. Zhao, Q. Song, W. Liu, Y. Sun, "Overview of dual-active-bridge isolated bidirectional DC-DC converter for high-frequency-link power-conversion system", in IEEE Trans. Power Electronics, vol. 29, no. 8, pp. 4091-4106, 2014. DOI: 10.1109/TPEL.2013.2289913.

[9] A. Abu-Siada, "High frequency transformer modelling using state space representation for FRA studies", Int. Symp. on Diag. for Elect. Mac., Power Electronics and Drives, 2017, pp. 422-426. DOI: 10.1109/DEMPED.2017.8062389.

[10] J. Smajic, M. Bucher, T. Franz, B. Cranganu-Cretu, A. Shoory, J. Tepper, "Modeling of frequency dependent parameters in time domain high frequency transformer simulations", Procedia Engineering, vol. 202, pp. 251-263, 2017. DOI: 10.1016/j.proeng.2017.09.712.

[11] G. L. Piazza, R. L. Alves, C. H. I. Font, I. Barbi, "Resonant circuit model and design for a high frequency high voltage switched-mode power supply", Brazilian Power Electronics Conf., Bonito-Mato Grosso do Sul, pp. 326-331, 2009. DOI: 10.1109/COBEP.2009.5347638.

[12] R. Sotner, N. Herencsar, J. Jerabek, A. Kartci, J. Koton, T. Dostal, "Pseudo-differential filter design using novel adjustable floating inductance simulator with electronically controllable current conveyors", Elektronika ir Elektrotechnika, vol. 23, pp. 31-35, 2017. DOI: 10.5755/j01.eie.23.2.17996.

[13] D. Prasad, D. R. Bhaskar, A. K. Singh, "New grounded and floating simulated inductance circuits using current differencing transconductance amplifiers", Radioengineering, vol. 19, no. 1, pp. 194-198, 2010.

[14] M. A. Ibrahim, S. Minaei, E. Yuce, N. Herencsar, J. Koton, "Lossy/lossless floating/grounded inductance simulation using one DDCC", Radioengineering, vol. 21, no. 1, pp. 3-10, 2012.

[15] D. Prasad, D. R. Bhaskar, "Grounded and floating inductance simulation circuits using VDTAs", Circuits and Systems, vol. 3, no. 4, pp. 342-347, 2012. DOI: 10.4236/cs.2012.34048.

[16] N. Herencsar, A. Lahiri, J. Koton, K. Vrba, R. Sotner, "New floating lossless inductance simulator using Z-copy current follower transconductance amplifiers", in Proc. 22nd Int. Conf. Radioelektronika, Brno, pp. 1-4, 2012. 
[17] A. Guney, H. Kuntman, "New floating inductance simulator employing a single ZC-VDTA and one grounded capacitor", 9th IEEE Int. Conf. Design \& Technology of Integrated Systems in Nanoscale Era, Santorini, 2014, pp. 1-2. DOI: 10.1109/DTIS.2014.6850643.

[18] K. Longsomboon, W. Petchmaneelumka, T. Cheypoca, V. Riewruja,
"OTA-based electronically variable floating inductance simulator", 11th Int. Conf. Control, Automation and Systems, Gyeonggi-do, 2011, pp. 221-224.

[19] A. Yesil, "Transconductance based new active element design and its applications", MSc. Dissertation, Dept. Electrical and Electronics Eng., Istanbul University, Istanbul, 2011. 